Available online on 15.01.2021 at http://jddtonline.info
Oc 2011-21, publisher and licensee JDDT, This is an Open Access article which permits
unrestricted non-commercial use(CC By-NC), provided the original work is properly cited
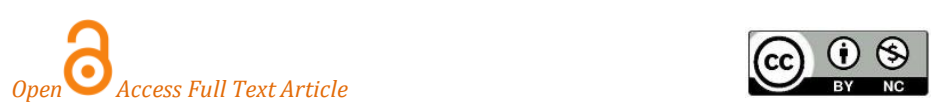

Research Article

\title{
Formulation and Evaluation of Ketorolac Tromethamine Mouth Dissolving Tablets
}

\author{
Bindal Rishabh* and Indurkhya Arpna \\ Sri Aurobindo Institute of Pharmacy, Indore, Madhya Pradesh (India) 453555
}

\begin{abstract}
Article Info:
Article History:

Received 13 Nov 2020;

Review Completed 23 Dec 2020

Accepted 30 Dec 2020;

Available online 15 Jan 2021

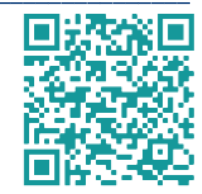

Cite this article as:

Bindal R, Indurkhya A, Formulation and

Evaluation of Ketorolac Tromethamine Mouth

Dissolving Tablets, Journal of Drug Delivery and

Therapeutics. 2021; 11(1):60-64

DOI: http://dx.doi.org/10.22270/jddt.v11i1.4502

*Address for Correspondence:

Rishabh Bindal, Sri Aurobindo Institute of

Pharmacy, Indore, Madhya Pradesh, India453555

Abstract

Due to more versatility and comfort, mouth dissolving tablets are the most advanced type of oral solid dosage forms. Compared to conventional tablets, it increases the effectiveness of APIs by dissolving within a minute in the oral cavity after contact with less saliva, without chewing and without the need for water for administration. Mouth Dissolving Tablets of Ketorolac tromethamine were prepared by direct compression method using various superdisintegrants like crospovidone, Croscarmellose sodium, and Sodium starch glycolate in different concentrations. Prepared tablets were evaluated for hardness, friability, weight variation, disintegration time, wetting time and in vitro drug release. Results of pre-compression and post-compression studies of all formulations were found within the standard limits. The tablets of all the batches were found to release more than $80 \%$ of drug in 5 minutes, which is the desired quality of mouth dissolving tablets that helps in faster absorption of the drug and quick onset of therapeutic effect. The the order of dissolution of various disintegrants was found to be Crospovidone> SSG> CCS. There was no significant variation in drug content of drug during stability studies for selected batch F3 in accelerated conditions over three months. It was concluded from the study that fast release of Ketorolac tromethamine from formulation F3 may reduce onset of drug action with better patient compliance.
\end{abstract}

Keywords: Crospovidone, Croscarmellose sodium, Ketorolac tromethamine, Mouth dissolving tablets, Sodium starch glycolate, superdisintegrants.

\section{INTRODUCTION}

Over the past few years, extensive efforts have been made in designing dosages forms with improved patient compliance, enhanced therapeutic effectiveness, reduced side effects, and reducing dosage regimen with less toxicity to treat many acute and chronic diseases. Several rapidly disintegrating drug delivery systems are developed and commercialized 1-3. The oral drug delivery segment has resulted in the transition from simple conventional tablets or capsules to modified release tablets or capsules into Mouth dissolving tablets (MDTs). Mouth dissolving tablet technology has gained a lot of attention among the plenty of avenues explored for rapid drug release products ${ }^{4-7}$.

The diseases like short term management of moderate to moderately severe acute pain, including post-surgical pain (such as general orthopedic and dental surgery), and acute musculoskeletal trauma pain need to be treated with pain killers. Presently wide range of NSAIDs is available to treat such pain and analgesia. Ketorolac tromithamine (KRT) is a member of the pyrrolopyrrole group of NSAIDs that exhibits analgesic, anti-inflammatory and antipyretic activity $8-10$. It inhibits the cyclooxygenase enzyme system and hence prostaglandin synthesis. It has more pronounced analgesic activity than most NSAIDs. The present investigation was focused on formulation and evaluation of mouth dissolving tablets of Ketorolac tromithamine and thus relieving pain immediately.

\section{MATERIALS AND METHODS}

\section{Materials}

Ketorolac tromethamine was received as a gift sample from McW Healthcare Private Limited, Indore. Crospovidone, Croscarmellose sodium, and Sodium starch glycolate were purchased from SD-Fine chemicals, Mumbai. All other chemicals and reagents were of analytical reagent grade.

\section{Methods}

\section{Pre-formulation studies}

Particular fundamental physical and chemical properties of the drug molecule and other derived properties of the drug powder must be determined before producing dosage forms. The preformulation procedure is the first step in the production of a drug's dosage forms.

\section{Melting point determination}

A capillary melting point apparatus (Tempo, Mumbai) was used to determine the melting point of the drug. Capillary tube was filled with drug sample and placed in melting point apparatus with a thermometer and the temperature was noted when the drug started melting. 


\section{Preparation of Calibration Curve}

Accurately weighed $100 \mathrm{mg}$ of KRT was dissolved in PBS pH 6.8 and volume was made up to $100 \mathrm{ml}$, resulting in a stock solution of $1000 \mu \mathrm{g} / \mathrm{ml}$. Then, $10 \mathrm{ml}$ of this stock solution was further diluted to $100 \mathrm{ml}$ with PBS $\mathrm{pH} 6.8$ to get stock solution of $100 \mu \mathrm{g} / \mathrm{ml}$ concentration. Stock solution was taken in aliquots of $0.5 \mathrm{ml}, 1.0 \mathrm{ml}, 1.5 \mathrm{ml}$ upto $2.5 \mathrm{ml}$ in to a series of $10 \mathrm{ml}$ volumetric flasks and volume was made up to the mark with PBS $\mathrm{pH}$ 6.8. The solutions were filtered through Whatman filter paper no. 1 and filtrate was analyzed at $\lambda$ max $322 \mathrm{~nm}$ using UV visible spectrophotometer ${ }^{10}$. PBS pH 6.8 was used as blank solution. The standard curve was plotted between absorbance and concentration.
Formulation of mouth dissolving tablets of Ketorolac Tromethamine

All the ingredients were powdered separately in a dry, clean porcelain mortar and passed through \# 60 mesh sieve and mixed well in geometrical ratio. Different preliminary batches of MDT tablets were prepared by mixing all ingredients with different superdisintegrants (Table 1). Powder mixture of KRT, with one of the superdisintegrant crospovidone, crosscarmellose sodium and sodium starch glycollate were dry blended for 20min followed by addition of mannitol and aspartame. The mixtures were then mixed with magnesium stearate and talc and further blended for 10 min and resultant powder blend was directly compressed using rotary tablet machine with $9 \mathrm{~mm}$ flat round punches to obtain the MDT tablets containing 10mg of KRT 11-12.

Table 1: Composition of MDTs of Ketorolac tromethamine

\begin{tabular}{|l|l|l|l|l|l|l|l|l|l|}
\hline \multirow{2}{*}{ Ingredients (mg) } & \multicolumn{6}{l}{ Formulation code } \\
\cline { 2 - 10 } & F1 & F2 & F3 & F4 & F5 & F6 & F7 & F8 & F9 \\
\hline Ketorolac tromethamine & 10 & 10 & 10 & 10 & 10 & 10 & 10 & 10 & 10 \\
\hline Crospovidone & 5 & 10 & 15 & - & - & - & - & - & - \\
\hline SSG & - & - & - & 5 & 10 & 15 & - & - & - \\
\hline CCS & - & - & - & - & - & - & 5 & 10 & 15 \\
\hline Mannitol & 72 & 67 & 62 & 72 & 67 & 62 & 72 & 67 & 62 \\
\hline Aspartame & 8.0 & 8.0 & 8.0 & 8.0 & 8.0 & 8.0 & 8.0 & 8.0 & 8.0 \\
\hline Magnesium stearate & 1.0 & 1.0 & 1.0 & 1.0 & 1.0 & 1.0 & 1.0 & 1.0 & 1.0 \\
\hline Talc & 4.0 & 4.0 & 4.0 & 4.0 & 4.0 & 4.0 & 4.0 & 4.0 & 4.0 \\
\hline Tablet total weight & 100 & 100 & 100 & 100 & 100 & 100 & 100 & 100 & 100 \\
\hline
\end{tabular}

\section{Evaluation of prepared mouth dissolving tablets}

\section{Pre Compression Parameters}

\section{Bulk density (BD)}

It is the ratio of total mass of powder to the bulk volume of powder. 25g of KRT blend with excipients was weighed and transferred into $50 \mathrm{ml}$ measuring cylinders without tapping during transfer the volume occupied by blend was measured. Bulk density was calculated by following formula:

\section{Bulk density $=$ Mass of the blend / Untapped Volume}

\section{Tapped density (TD)}

It is the ratio of total mass of the powder to the tapped volume of the powder. 25g of KRT blend were weighed and taken into graduated measuring cylinders. Initial volume occupied by drug blends was noted down. Then cylinder was subjected to 500 taps in tapped density tester (Electro Lab USPII) according to USP. Tapped density was calculated using the tapped volume and mass of powdered drugs using following formula:

Tapped density = Mass of the blend $/$ Tapped Volume

\section{Flow properties (Angle of Repose)}

The angle of repose of powder was determined by the funnel method. $25 \mathrm{~g}$ accurately weighed drug blend with excipients was taken in a funnel. The height of the funnel was adjusted in such a way that the tip of the funnel just touches the apex of the heap of the powder. The powder was allowed to flow through the funnel freely onto the surface. The diameter of the powder cone was measured and angle of repose was calculated using the following equation.

$$
\theta=\tan ^{-1}(\mathrm{H} / \mathrm{R})
$$

Where, $\mathrm{H}$ and $\mathrm{R}$ are the height and radius of the pile.

\section{Compressibility Index (Carr's index-CI)}

It is indirectly related to the relative flow rate, cohesiveness and particle size. It is simple, popular and fast method of predicting powder flow characteristics. It is based on the apparent bulk density and the tapped density, the percentage compressibility of the bulk drug was determined by the following formula-

$$
\text { Carr's index }(\%)=\frac{\text { Tapped density-Bulk density }}{\text { Tapped density }} \text { X } 100
$$

\section{Determination of Hausner ratio (HR)}

The Hausner's ratio is a number that is correlated to the flow ability of a powder or granular material. It is measurement of frictional resistance of the drug. It was determined by the ratio of tapped density and bulk density.

$$
\text { Hausner Ratio }=\frac{\text { Tapped density }}{\text { Bulk density }}
$$

\section{Post Compression Parameters 13-14}

\section{Hardness}

The tablet should be stable to mechanical stress during handling and transportation. Hardness $\left(\mathrm{Kg} / \mathrm{cm}^{2}\right)$ of MDTs was determined by Monsanto hardness tester. 


\section{Friability (F)}

MDT formulations (20) were weighed and placed in the Roche Friabillator that revolves at $25 \mathrm{rpm}$ for 4 minutes dropping the from a distance of six inches with each revolution. After operation the tablets were de-dusted and reweighed. The $\%$ friability was then calculated by the following formula-

$$
\mathrm{F}=\frac{\text { Initial Weight }- \text { Final weight }}{\text { Initial Weight }} \times 100
$$

\section{Weight variation test}

MDT formulations (20) were individually weighed, calculated the average weight, and compared the individual tablet weights to the average. The tablets met the USP tests that were not more than 2 tablets were outside the percentage limit and no tablets differed by more than 2 times the percentage limit. The percentage difference in the weight variation should be within the permissible limits $( \pm 7.5 \%)$.

\section{Thickness}

Tablets of each batch were selected and measured for thickness using verniour caliper.

\section{Disintegration time}

Disintegration time was measured using disintegration test apparatus (Electrolab ED-2L, Mumbai, India). Single tablet was placed in each of the six tubes of the basket, insert disc and operate the apparatus for the specified time, using distilled water maintained at $37 \pm 2^{\circ} \mathrm{C}$ as the immersion fluid. The time in second was noted when tablets disintegrate completely.

\section{Drug content}

Total 10 tablets were weighed and powder equivalent to $10 \mathrm{mg}$ of KRT was weighed and dissolved in PBS pH 6.8 then filtered through Whatman filter paper. Solution was analyzed for KRT content by UV Spectrophotometer at 322nm using PBS pH 6.8 as blank.

\section{Wetting time}

The wetting time of the tablets can be measured using a simple procedure. Five circular tissue papers of $10 \mathrm{~cm}$ diameter are placed in a petridish with a $10 \mathrm{~cm}$ diameter. 10 $\mathrm{ml}$ of PBS pH 6.8 was poured into the tissue paper placed in the petridish. A tablet is carefully placed on the surface of the tissue paper. The time required for water to reach upper surface of the tablet is noted as a wetting time.

\section{In Vitro Dissolution Studies of MDTs}

The developed MDT formulations of ketorolac were subjected to release studies using USP-II dissolution apparatus (Electrolab TDT-06 P, Mumbai, India) at 50 RPM 14-15. Dissolution medium used was $900 \mathrm{ml}$ PBS pH 6.8 maintained at $37 \pm 0.5^{\circ} \mathrm{C}$, which was found to provide sink conditions. The $5 \mathrm{ml}$ samples were withdrawn at different time intervals and replaced with an equivalent amount of fresh medium. The dissolution samples, after filtration through $0.45-\mathrm{mm}$ filters, were analyzed using a validated UV spectroscopic method at $322 \mathrm{~nm}$.

\section{Stability Studies}

The studies were conducted as per ICH guidelines which recommend a temperature of $40 \pm 2 \circ \mathrm{C}$, a relative humidity of $75 \pm 5 \%$ and period of 3 months for accelerated stability studies. However, the stability was also assessed at $4 \pm 1^{\circ} \mathrm{C}$ (refrigerated condition) and at $25 \pm 2{ }^{\circ} \mathrm{C}$ with $60 \pm 5 \%$ relative humidity. The sampling time was kept at 1, 2 and 3 months. The studies were performed using stability chamber (Thermo Lab, Mumbai). Changes in the appearance and drug content of the stored films were investigated during the period and after 3 month 15 .

\section{RESULTS AND DISCUSSION}

\section{Preformulation studies}

It was observed that the melting point of the drugs was found to be $166^{\circ} \mathrm{C}$ which is similar to the reported value and proved that the received drug sample meets the reported properties. The absorption maximum of KRT was measured by UV/Visible spectrophotometer and found to be $322 \mathrm{~nm}$. Calibration curve was prepared and linearly regressed. The correlation coefficient for standard curves was found to be very near to one which indicates good co-linear correlation between concentration $5-25 \mu \mathrm{g} / \mathrm{ml}$ (Table 2 and Figure 1). Hence, drugs are following Beer Lambert Law in the above range.

Table 2: Calibration curve of KRT in PBS pH 6.8 at $322 \mathrm{~nm}$

\begin{tabular}{|c|c|c|}
\hline S. No. & Drug Conc. $(\boldsymbol{\mu g} / \mathbf{m l})$ & Absorbance \\
\hline 1. & 5 & 0.1210 \\
\hline 2. & 10 & 0.2374 \\
\hline 3. & 15 & 0.3608 \\
\hline 4. & 20 & 0.4822 \\
\hline 5. & 25 & 0.6132 \\
\hline
\end{tabular}

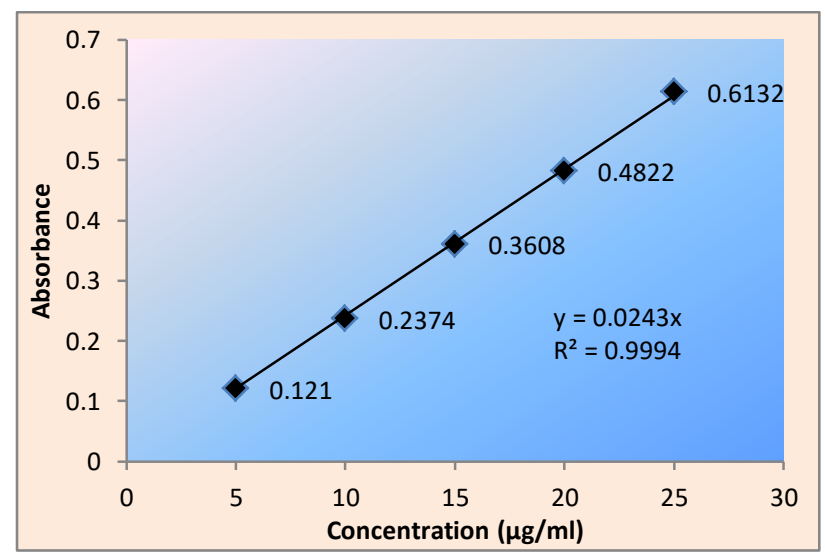

Figure 1: Calibration curve of KRT in PBS pH 6.8 at $322 \mathrm{~nm}$

\section{Pre-compression evaluations}

Pre-compression evaluations were done to ensure the flow properties of the powder blend. The powder blend's good flow properties will yield the tablets of desired quality and ease the tableting process. The bulk density of all formulations ranges from $0.36 \mathrm{~g} / \mathrm{cm}^{3}$ to $0.45 \mathrm{~g} / \mathrm{cm}^{3}$. The tapped density of all the formulations ranges from $0.45 \mathrm{~g} / \mathrm{cm} 3$ to $0.56 \mathrm{~g} / \mathrm{cm} 3$. The angle of repose of all formulations was found in a range of $25^{\circ} .5^{\prime}$ to $29^{\circ} .6^{\prime}$. The compressibility index of all the formulations ranges from 8.69 to 30.35 . The Hausner's ratio for powder blends of all nine formulations ranges from 1.09 to 1.43 . The results indicate that the powder blends of all nine formulations had good flow properties. The various pre-compression parameters are shown in Table 3. 
Table 3: Pre-compression characterization of KRT blend

\begin{tabular}{|c|c|c|c|c|c|}
\hline \multirow[t]{2}{*}{ Formula Code } & \multicolumn{5}{|c|}{ Parameters } \\
\hline & Angle of Repose ( $\theta$ ) & $\mathrm{BD}(\mathrm{g} / \mathrm{ml})$ & TD (g/ml) & CI (\%) & HR \\
\hline F-1 & 28.2 & 0.36 & 0.49 & 26.53 & 1.36 \\
\hline F-2 & 25.5 & 0.39 & 0.56 & 30.35 & 1.43 \\
\hline F-3 & 28.1 & 0.39 & 0.48 & 18.75 & 1.23 \\
\hline F-4 & 29.6 & 0.42 & 0.46 & 8.69 & 1.09 \\
\hline F-5 & 25.7 & 0.40 & 0.46 & 13.04 & 1.15 \\
\hline F-6 & 27.2 & 0.38 & 0.45 & 15.55 & 1.18 \\
\hline F-7 & 27.1 & 0.41 & 0.53 & 22.64 & 1.29 \\
\hline F-8 & 27.8 & 0.39 & 0.46 & 15.21 & 1.17 \\
\hline F-9 & 27.4 & 0.45 & 0.54 & 16.66 & 1.20 \\
\hline
\end{tabular}

\section{Post-compression evaluations}

The hardness for tablets of all the formulations was found to be less than $3 \mathrm{~kg} / \mathrm{cm}^{2}$. The results friability indicated that tablets of all batches have friability below 1\% and hence passes the test. The weight variation test was carried out to ensure that the tablets of each formulation were of uniform weight, which will indicate the uniform distribution of contents of each formulation's powder blends. The weight variation for tablets of all formulations was found to be within the range of $7.5 \%$. The results indicate that all tablets of each formulation were of uniform weight. The thickness for tablets of all nine formulations was found to be 2.2 to
$2.5 \mathrm{~mm}$. The drug contents for tablets of all the formulations ranges from $95.46 \%$ to $98.84 \%$. (Table 4 ).

The disintegration time was the time taken by the tablet to break down into small particles, in the presence of an aqueous medium. It varies with the type and concentration of the superdisintegrants incorporated in the formulation. As the name implies, disintegration time was the prime most criteria for mouth dissolving tablet, which should be less than 30 secs to 3 minutes as per the standards. The results indicate that the disintegration time for tablets of all formulations is within limits. Results of wetting time test indicated that wetting time of all tablets and the water absorption ratio were within limits (Table 4).

Table 4: Post-compression evaluation of MDTs of KRT

\begin{tabular}{|c|c|c|c|c|c|c|c|c|c|}
\hline Parameter & F1 & F2 & F3 & F4 & F5 & F6 & F7 & F8 & F9 \\
\hline Hardness (Kg/cm $)$ & 2.8 & 2.7 & $\mathbf{2 . 8}$ & 3.1 & 2.9 & 2.9 & 3.0 & 2.8 & 2.7 \\
\hline Weight (mg) & 97.8 & 97.8 & $\mathbf{9 9 . 2}$ & 97.4 & 98.5 & 98.2 & 100.8 & 98.6 & 97.5 \\
\hline Thickness (mm) & 2.5 & 2.4 & $\mathbf{2 . 4}$ & 2.5 & 2.3 & 2.2 & 2.5 & 2.5 & 2.4 \\
\hline Friability (\%) & 0.68 & 0.66 & $\mathbf{0 . 6 2}$ & 0.67 & 0.66 & 0.62 & 0.68 & 0.65 & 0.63 \\
\hline \%Drug Content & 95.20 & 98.84 & $\mathbf{9 8 . 8 4}$ & 98.15 & 98.02 & 98.26 & 97.58 & 98.18 & 98.37 \\
\hline Disintegration Time (Sec) & 63 & 46 & $\mathbf{2 1}$ & 74 & 57 & 35 & 64 & 48 & 36 \\
\hline Wetting time (Sec) & 42 & 34 & $\mathbf{3 0}$ & 44 & 38 & 31 & 44 & 39 & 32 \\
\hline
\end{tabular}

In vitro drug release from MDTs was carried out in $\mathrm{pH} 6.8$ phosphate buffer. The superdisintegrants were added to the solid dosage formulations to enhance the disintegration time, thereby enhancing the faster release of active drug from its dosage form, which ultimately resulted in enhanced absorption and bioavailability of the drug. The maximum drug release at a period of five minutes was noted for all the formulations. The results indicate that all the formulation's drug release was found to be above $80 \%$ in five minutes except for formulations (F1 and F2). The release rate of the three superdisintegrants was in the order of Crospovidone> Sodium Starch Glycolate> Croscarmallose (Table 5 and Figure 2-4).

Table 5: In vitro drug release from MDTs of KRT

\begin{tabular}{|c|c|c|c|c|c|c|c|c|c|}
\hline \multirow{2}{*}{$\begin{array}{c}\text { Dissolution } \\
\text { time (Min) }\end{array}$} & \multicolumn{9}{|c|}{ Cumulative \% Drug Release(n=3) } \\
\cline { 2 - 10 } & $\mathbf{F 1}$ & F2 & F3 & F4 & F5 & F6 & F7 & F8 & F9 \\
\hline $\mathbf{0}$ & 0 & 0 & 0 & 0 & 0 & 0 & 0 & 0 & 0 \\
\hline $\mathbf{2}$ & $44.72 \pm 1.4$ & $48.88 \pm 2.6$ & $49.12 \pm 4.3$ & $42.23 \pm 3.4$ & $47.27 \pm 3.2$ & $48.62 \pm 2.1$ & $45.08 \pm 2.8$ & $45.56 \pm 1.5$ & $48.76 \pm 2.6$ \\
\hline $\mathbf{5}$ & $81.61 \pm 4.2$ & $86.23 \pm 4.3$ & $92.73 \pm 3.8$ & $80.76 \pm 1.3$ & $83.76 \pm 5.5$ & $91.65 \pm 3.5$ & $83.15 \pm 2.2$ & $85.51 \pm 3.6$ & $88.89 \pm 4.2$ \\
\hline $\mathbf{1 0}$ & $94.26 \pm 3.7$ & $96.42 \pm 3.4$ & $99.82 \pm 5.8$ & $92.28 \pm 5.6$ & $96.47 \pm 5.2$ & $98.96 \pm 2.6$ & $90.38 \pm 1.2$ & $94.25 \pm 3.8$ & $97.33 \pm 2.7$ \\
\hline
\end{tabular}




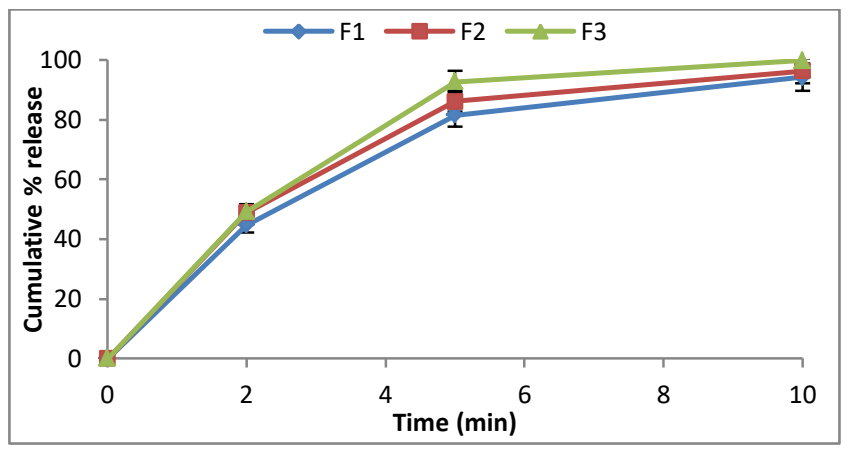

Figure 2: Comparative drug release from formulations F1-F3

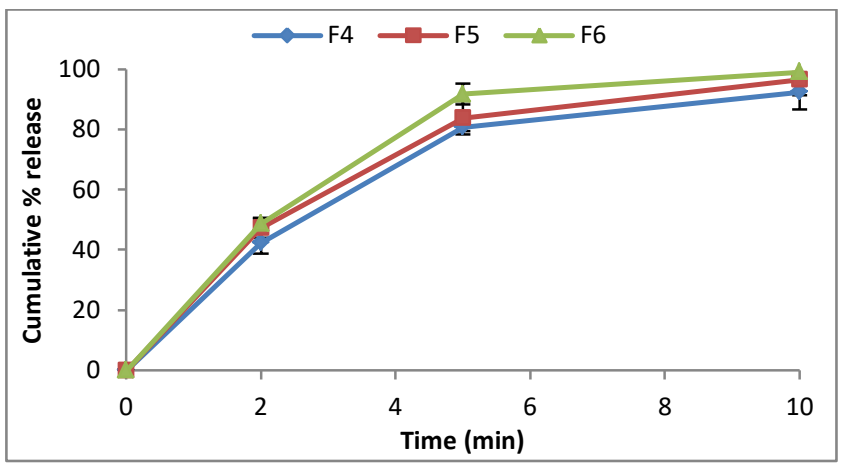

Figure 3: Comparative drug release from formulations F4-F6

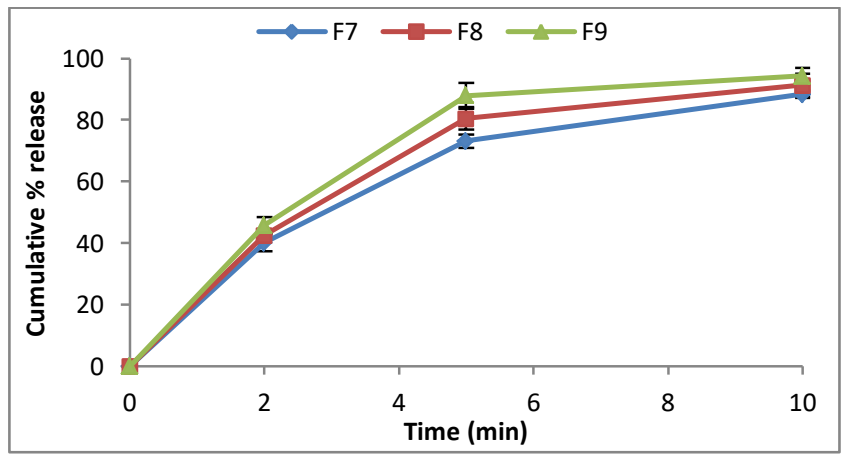

Figure 4: Comparative drug release from formulations F7-F9

Stability studies were performed on best selected formulation F3 on the basis of drug release profile. Formulation F3 was exposed to different storage conditions to determine any changes in final formulation. Initial drug content was considered to be $100 \%$. It was found that the percent drug content after a period of 3 months for KRT was $99.61 \pm 0.34 \%$ at $4 \pm 1{ }^{\circ} \mathrm{C}$ whereas it was $99.52 \pm 1.3 \%$ at $25 \pm 2^{\circ} \mathrm{C}$ \& $60 \pm 5 \%$ respectively. On the other hand it was $99.14 \pm 1.6 \%$ at $40 \pm 2{ }^{\circ} \mathrm{C} \& 75 \pm 5 \%$. These observations indicate that the formulation is fairly stable with respect to the drug content at all temperatures and conditions of storage.

\section{CONCLUSIONS}

The aim of the present study was design formulation and evaluation of mouth dissolving tablets of Ketorolac tromethamine using various superdisintegrants. Mouth dissolving tablets were prepared by direct compression method and evaluated for different physicochemical properties. All formulations showed good results for precompression and post-compression parameters. The tablets of all the batches were found to release more than $80 \%$ in 5 minutes, which is the desired quality of mouth dissolving tablets that helps in faster absorption of the drug and quick onset of therapeutic effect. The dissolution pattern of various disintegrants used in the formulation was found to be in the order of Crospovidone> SSG > CCS. Based on physicochemical parameters and in vitro release profile formulation F3 was considered as the best formulation. The conclusion from all encouraging results reaches that mouth dissolving tablets of Ketorolac tromethamine may be more suitable for quicker onset of action and better patient compliance.

\section{ACKNOWLEDGMENT}

The authors would like to thank Sri Aurobindo institute of Pharmacy, Indore for the support and providing all facilities to perform the above research work.

\section{CONFLICTS OF INTEREST}

There are no conflicts of interest.

\section{REFERENCES}

1. Parashar AK, Kakde D, Chadhar V, Devaliya R, Shrivastav V, Jain UK, "A review on Solid Lipid Nanoparticles (SLN) for controlled and targeted delivery of medicinal agents" CRPS online, 2011; 31: 37-47.

2. Rathore R, Gupta AK, Parashar AK, "Formulation and Evaluation of fast dissolving films of Granisetron Hydrochloride" Journal of Drug Delivery and Therapeutics, 2019; 9(2-A): 36-38.

3. Tiwari G, Tiwari R, Sriwastawa B, "Drug delivery systems: An updated review" IJPI, 2012; 2(1): 2-11.

4. Ghosh T, Ghosh, A, Prasad D, "A review on new generation orodispersible tablets and its future prospective" IJPPS, 2010; 3(1): 1-7.

5. Earle RR, Ayalasomayajula LU, Raju AN, Kumari KT, Kumar PR, "Formulation and evaluation of diclofenac sodium orodispersible tablets using different superdisintegrants by direct compression technique" Der Pharmacia Lettre, 2016; 8(8): 227-238.

6. Santosh RK, Kumari A, "Fast dissolving tablets: waterless patient compliance dosage forms" Journal of Drug Delivery and Therapeutics, 2019; 9(1): 303-317. DOI https://doi.org/10.22270/jddt.v9i1.2292

7. Malang M, Jain N, Koshta A, Malviya S, Kharia A. "Formulation and evaluation of fast dissolving tablet of paracetamol and chlorpheniramine maleate" IJPSR, 2020; 11(3): 1232-42.

8. Sangeetha G, Mahesh PG, Chanthin K, Lokesh M, Ameen S, "Formulation and evaluation of fast dissolving tablet of ketorolac tromethamine" AJPCR, 2018; 11: 163-9.

9. Raina B, Sharma A, Bajwa PS, "Formulation evaluation and optimization of fast disintegrating tablets of ketorolac tromethamine" JPI, 2018; 48: 685-695.

10. Haranath, "Formulation and optimization of ketorolac tromethamine $\mathrm{HCl}$ fast disintegrating tablets by experimental design" IRJP, 2019; 10(7): 79-86.

11. Santosh RK, Kumari A, "Superdisintegrant: crucial elements for mouth dissolving tablets" Journal of Drug Delivery and Therapeutics, 2019; 9(2): 461-468. DOI https://doi.org/10.22270/jddt.v9i2.2480

12. Pawar C, Mutha SS, Bhise SV, Borawake PD, "Formulation and evaluation of mouth dissolving tablet of meloxicam using natural superdisintegrants. AJPCR, 2020; 13(2): 197-03.

13. Gamal M, Zayed AS, Rasoulae M, Ibrahimac M, "In vitro and in vivo characterization of domperidone-loaded fast dissolving buccal films" SPJ, 2020; 28(3): 266-273.

14. Damodar R, Movva B, Mallikarjun PN, Chaitanya P, Kona N, Varsha PV, "Formulation and evaluation of fast dissolving tablets of diclofenac sodium by novel hole technology" Mol Pharm Org Process Res, 2014; 2: 1-6.

15. Ratnaparkhi MP, "Formulation and development of taste masked orally disintegrating tablets of perindopril erbumine by direct compression method" PAA, 2012; 3:162-172. 